\title{
ASSESSMENT OF DEVELOPMENT OF ADOLESCENT VOLLEYBALL PLAYERS' JUMPING ABILITY
}

\author{
Raini Stamm, Meelis Stamm, Madis Mets \\ School of Natural Sciences and Health, Tallinn University
}

\section{ABSTRACT}

The aim of the study was to find the influence of Prof. A. Belyayev and L. Bulykina's a month-and-a-half vertical jumping ability development programme on adolescent volleyball players aged 12-14 years.

The subjects in the experimental group were 15 adolescent volleyball players whose mean age was 12.9 years -7 boys whose initial mean running jump result was $52.9 \mathrm{~cm}$ and 8 girls whose mean running jump result was $36.9 \mathrm{~cm}$. The control group consisted of 13 players -3 boys whose initial mean running jump result was $54.3 \mathrm{~cm}$ and 10 girls whose mean running jump result was $47 \mathrm{~cm}$.

The study consists of three parts; in the first part, the subjects' anthropometric variables and running and standing jump ability were measured. Thereafter, the volleyball players of the experimental group attended a programme that lasted for 54 days, after which the children's anthropometric variables and jumping ability were measured again.

The results showed that the vertical jumping ability development programme proved effective. It improved girls' and boys' mean vertical standing jump result by $6.8 \mathrm{~cm}$ and vertical jump from attack steps by $6.5 \mathrm{~cm}$. Boys improved their vertical standing jump result by $6.2 \mathrm{~cm}$ and vertical jump from attack steps by $7.8 \mathrm{~cm}$. Girls' vertical standing jump result improved by $7.4 \mathrm{~cm}$ and vertical jump from attack steps by $5.1 \mathrm{~cm}$; the changes were statistically significant.

In the control group, jumping ability did not change statistically significantly, considering the mean results of the groups.

A. V. Belyayev and L. Bulykina's jumping ability development programme proved to be suitable to be used in an adapted version for developing 12-14-year-old volleyball players' vertical jumping ability.

Keywords: jumping ability; adolescent; volleyball player 


\section{INTRODUCTION}

Vertical jump is used in volleyball for performing three technical elements serve, block and spike. In present-day volleyball, second pass is also often performed from jump, as this makes the game faster, and the opposite team's blockers have to cope with a time deficit while choosing the position. Good vertical jumping ability enables the player to contact the ball higher than the net and, thus, makes the spike easier and more efficient [4]. Therefore, many tests and studies have been performed on volleyball players to find the most suitable methods of testing and training, which simultaneously would minimise the possibility of injuries $[2,5,3]$.

The aim of the study was to find the influence of Prof. A. Belyayev and L. Bulykina's vertical jumping ability development programme on adolescent volleyball players aged 12-14 years. For this, the anthropometric variables and jumping ability of adolescent volleyball players attending Kadrina Sports Club and Kalev Sports Society were measured. Then, the experimental group was subjected to the jumping ability development programme lasting for a month and a half, and thereafter, the jumping ability of both experimental and control groups was measured again, and changes in jumping ability were assessed.

\section{MATERIAL AND METHODS}

\section{Subjects}

The sample under study consisted of children attending basic school; the volleyball experience of all of them was longer than two years. In total, there were 7 boys and 8 girls whose age was 12-14 years. Their volleyball practice where exercises to develop jumping ability were performed took place three times a week. The boys' mean age was 13 and of the girls' -12.8 years. The playing experience of all the girls participating in the study was 2 years. Five boys had an experience of 3 years and two boys -2 years.

The children of the control group practised at Kalev Sports Society in Tallinn. They were also a volleyball training group, which consisted of three boys and nine girls with the mean age 13.2 years. The students of the control group also underwent measuring of height and weight and hand reach and testing of jumping ability, but they did not participate in the 54-day jumping ability development programme. They had regular volleyball practice three times a week.

Children's height was measured to the precision of $0.1 \mathrm{~cm}$. Their weight was measured on electronic scales to the precision of $0.01 \mathrm{~kg}$. The volleyball 
players' parents had given their consent to the experiment. For measuring the jumping ability, Jatsuda's method was used where first the player's hand reach and then the height of the running and standing jump were measured [7]. To get the jump height, the player's standing hand reach is subtracted from the hand reach at jump.

\section{Method for jumping ability development}

As the method for jumping ability development, we used Prof. A. V. Belyayev and L. Bulykina's jumping ability development programme [1] in a somewhat simplified form, as the original programme was meant for male volleyballers playing in the championship league. For example, we replaced jumps onto a mat at the height of $90 \mathrm{~cm}$ with jumps onto a mat at $60 \mathrm{~cm}$.

The first stage (18 days). Jumping practice takes place every day. At each practice, the following jump exercises are performed: 2, 3, 4, 7. Dosage: each exercise -20 jumps, 2 series. Rest between series and exercises 1-2 minutes.

Second stage (18 days). Jumping practice takes place every other day. At each practice, the following jump exercises are performed: 1, 5, 8. Dosage: each exercise - 20 jumps, 2 series. Rest between series and exercises 2-3 minutes.

Third stage (18 days). Jumping practice takes place every other day. At each practice, the following jump exercises are performed: $6,9,10$. Dosage: each exercise -25 jumps, 3 series. Rest between exercises 2-3 minutes.

\section{CATALOGUE OF EXERCISES}

1. Jumps from half-squat with maximum effort (angle between lower and upper legs $130-140$ degrees).

2. Jumps onto the mat $(60 \mathrm{~cm})$.

3. Step jumps

4. Split jumps

5. Step-squat-jump (step, descent into low squat, from there, jump upwards with straight back, hands up)

6. Jumps upwards with taking straight legs forward

7. High knees run (at maximum speed, knees at right angle)

8. Jump across the bench with a turn from low squat to the other side of the bench into low squat (facing the bench all the time)

9. Imitation of block at the net

10. Attack steps with touching a mark above the head 


\section{RESULTS}

Before the jumping ability development programme, the mean height of the boys of the experimental group attending volleyball practice at Kadrina was $169.5 \mathrm{~cm}(\mathrm{SD}=8.2)$ and mean weight $63.1 \mathrm{~kg}(\mathrm{SD}=12.3)$. The height of the tallest boy was $172 \mathrm{~cm}$ and of the shortest $155.4 \mathrm{~cm}$. The heaviest boy weighed $79.1 \mathrm{~kg}$ and the lightest $48.2 \mathrm{~kg}$. The mean height of control group boys was $168.7 \mathrm{~cm}(\mathrm{SD}=15)$ and mean weight $66.9 \mathrm{~kg}(\mathrm{SD}=27.8)$. The height of the tallest boy was $181 \mathrm{~cm}$, of the shortest $152 \mathrm{~cm}$; the heaviest boy weighed $95.6 \mathrm{~kg}$ and the lightest $40.2 \mathrm{~kg}$.

After the jumping ability development programme, the mean height of the boys of the experimental group was $170 \mathrm{~cm}(\mathrm{SD}=8.2)$ and mean weight $63.7 \mathrm{~kg}$ $(\mathrm{SD}=12.3)$. The tallest boy $(172.8 \mathrm{~cm})$ had grown by $0.8 \mathrm{~cm}$ and the shortest boy $(155.9 \mathrm{~cm})$ by $0.5 \mathrm{~cm}$. The heaviest boy weighed $78.8 \mathrm{~kg}$ and the lightest $48.2 \mathrm{~kg}$. The arithmetic mean of the boys' height had increased by $0.5 \mathrm{~cm}$ and weight by $0.6 \mathrm{~kg}$. The mean height of control group boys after 54 days was $169.3 \mathrm{~cm}(\mathrm{SD}=15.3)$, which was $0.6 \mathrm{~cm}$ higher than at the first measuring. Their mean weight was $67 \mathrm{~kg}(\mathrm{SD}=27.9)$, having increased by $0.1 \mathrm{~kg}$.

Before the jumping ability development programme, the mean height of the girls in the Kadrina experimental group was $161.8 \mathrm{~cm}(\mathrm{SD}=4.8)$ and mean weight $53.7 \mathrm{~kg}(\mathrm{SD}=12.1)$. The height of the tallest girl was $168.3 \mathrm{~cm}$ and of the shortest $154 \mathrm{~cm}$. The heaviest girl weighed $72 \mathrm{~kg}$ and the lightest $39.2 \mathrm{~kg}$. The control group girls' mean height was $166.4 \mathrm{~cm}(\mathrm{SD}=7.1)$ and mean weight $60.4 \mathrm{~kg}(\mathrm{SD}=7.1)$. The height of the tallest girl was $174.8 \mathrm{~cm}$, of the shortest $156.3 \mathrm{~cm}$; the heaviest girl weighed $72.5 \mathrm{~kg}$ and the lightest girl $53.5 \mathrm{~kg}$.

After the jumping ability development programme, the girls' mean height was $162.2 \mathrm{~cm}(\mathrm{SD}=4.9)$; the arithmetic mean height had increased by $0.3 \mathrm{~cm}$. Their mean weight increased by $0.6 \mathrm{~kg}$ to $54.2 \mathrm{~kg}$ ( $\mathrm{SD}=10.8)$. After completing the programme, the height of the tallest girl was $168.3 \mathrm{~cm}$; the shortest girl $(154.5 \mathrm{~cm}$ ) had grown by $0.5 \mathrm{~cm}$. The heaviest girl weighed $71.2 \mathrm{~kg}$ and the lightest $40.2 \mathrm{~kg}$. The control group girls' mean height after 54 days was $167 \mathrm{~cm}$ $(\mathrm{SD}=7.3$ ), having increased by $0.6 \mathrm{~cm}$ compared to the initial data. Their mean weight was $60.5 \mathrm{~kg}(\mathrm{SD}=6.8)$, having increased by $0.1 \mathrm{~kg}$. The height of the tallest girl in the control group was $176 \mathrm{~cm}$, of the shortest $157 \mathrm{~cm}$; the heaviest girl weighed $72.5 \mathrm{~kg}$ and the lightest $53.5 \mathrm{~kg}$.

Kadrina Sports Club boys' mean hand reach before attending the programme was $218.3 \mathrm{~cm}(\mathrm{SD}=8.5)$. The highest hand reach was $229.4 \mathrm{~cm}$ and the lowest $206 \mathrm{~cm}$. In the control group, the mean hand reach was $219 \mathrm{~cm}$ $(\mathrm{SD}=21.1)$ - the highest $239 \mathrm{~cm}$ and the lowest $197 \mathrm{~cm}$. 
After completing the programme, Kadrina Sports Club boys' mean hand reach had increased by $0.4 \mathrm{~cm}$ and was $218.7 \mathrm{~cm}(\mathrm{SD}=8.7)$. The highest hand reach rose to $230 \mathrm{~cm}$ and the lowest to $206 \mathrm{~cm}$. The mean hand reach of the control group remained at $219 \mathrm{~cm}(\mathrm{SD}=2.19)$.

Kadrina Sports Club girls' mean hand reach before attending the programme was $207.3 \mathrm{~cm}$ (SD=9.5). The highest hand reach was $221.2 \mathrm{~cm}$ and the lowest $194.4 \mathrm{~cm}$. Control group girls' mean hand reach of was $212 \mathrm{~cm}$ $(\mathrm{SD}=7.3)$.

After completing the programme, Kadrina Sports Club girls' mean hand reach was $207.8 \mathrm{~cm}(\mathrm{SD}=9.6)$. The highest hand reach was $222.2 \mathrm{~cm}$ and the lowest $195.1 \mathrm{~cm}$. The mean hand reach in the control group was $212.9 \mathrm{~cm}$ ( $\mathrm{SD}=7.5$ ). The highest hand reach was $227 \mathrm{~cm}$ and the lowest $201 \mathrm{~cm}$.

\section{Characterisation of volleyball players' jumping ability before and after the programme}

Before the programme, Kadrina Sports Club boys' mean jumping ability from steps was $52.9 \mathrm{~cm}(\mathrm{SD}=10.6)$. The highest jump result was $67 \mathrm{~cm}$ and the lowest $42 \mathrm{~cm}$. The mean result of standing jump was $40.1 \mathrm{~cm}(\mathrm{SD}=6.7)$. The highest result was $47 \mathrm{~cm}$ and the lowest $30 \mathrm{~cm}$. In the control group, the boys' mean result of running jump was $54.3 \mathrm{~cm}(\mathrm{SD}=7.2)$. The highest result was $59 \mathrm{~cm}$ and the lowest $46 \mathrm{~cm}$.

After completing the programme, the mean jumping ability of Kadrina Sports Club boys from steps had increased by $7.8 \mathrm{~cm}$, being $60.7 \mathrm{~cm}(\mathrm{SD}=10.8)$ on average. The highest result was $74 \mathrm{~cm}$, which meant an improvement by $7 \mathrm{~cm}$, and the lowest $49 \mathrm{~cm}$, which was also an improvement by $7 \mathrm{~cm}$. The greatest development was seen in a boy who improved his result by $14 \mathrm{~cm}$. In standing jump, the boys' mean jumping ability increased by $6.2 \mathrm{~cm}$; the mean result was $46.3 \mathrm{~cm}(\mathrm{SD}=8.1)$. The mean result of the control group boys remained the same, being $54 \mathrm{~cm}(\mathrm{SD}=8.1)$. 


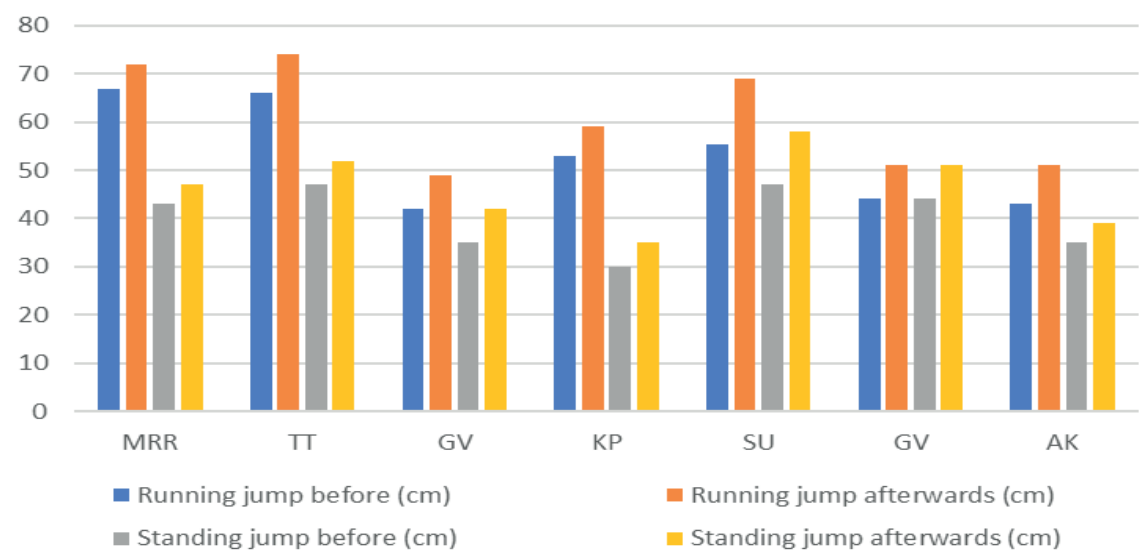

Figure 1. Jumping ability of experimental group boys (Kadrina Sports Club) before and after attending the programme

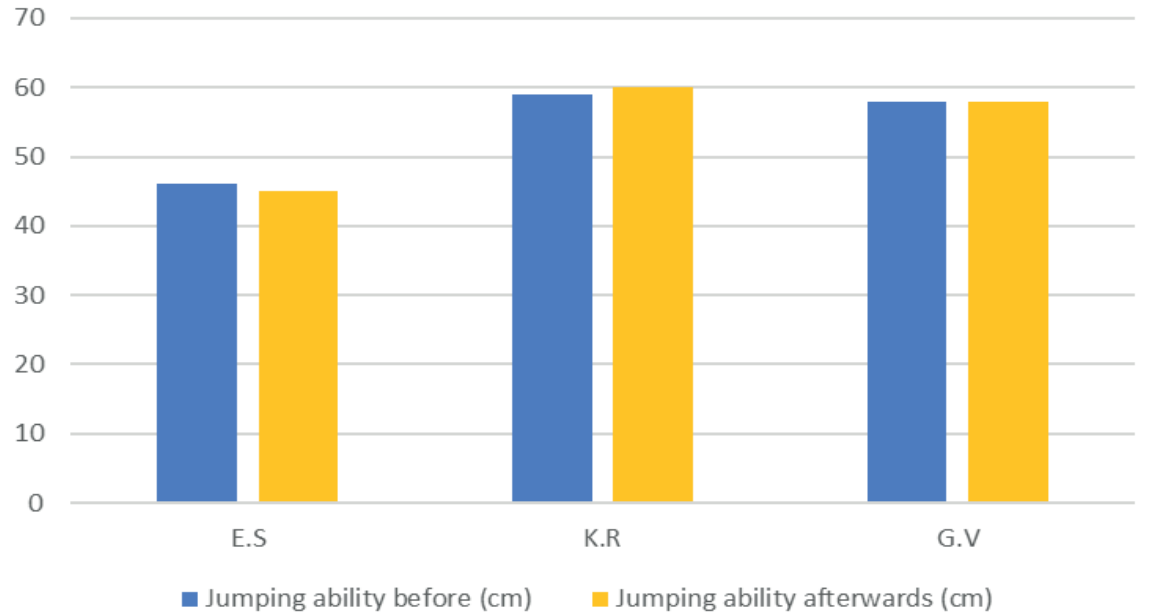

Figure 2. Control group boys' jumping ability from attack steps at the first and the second measuring

The girls' mean standing jump result before the programme was $31.4 \mathrm{~cm}$ ( $\mathrm{SD}=6.9$ ). The best standing jump result was $44 \mathrm{~cm}$ and the weakest $23 \mathrm{~cm}$. The mean running jump result was $36.9 \mathrm{~cm}(\mathrm{SD}=7.9)$. The highest result was $53 \mathrm{~cm}$ and the lowest $29 \mathrm{~cm}$. The mean result of control group girls from attack steps was $47 \mathrm{~cm}(\mathrm{SD}=3)$. The highest result was $53 \mathrm{~cm}$ and the lowest $44 \mathrm{~cm}$.

After completing the programme, the mean standing jump result of the experimental group of Kadrina Sports Club girls increased by $7.4 \mathrm{~cm}$, being $38.8 \mathrm{~cm}(\mathrm{SD}=5.9)$. The best result was $48 \mathrm{~cm}$, which meant an improvement 
by $4 \mathrm{~cm}$, and the lowest $32 \mathrm{~cm}$, which was an improvement by $9 \mathrm{~cm}$. The arithmetic mean result of jump from attack steps increased by $5.1 \mathrm{~cm}$; the best result was $58 \mathrm{~cm}$ and the weakest $34 \mathrm{~cm}$. In control group girls, the arithmetic mean remained the same, being $47 \mathrm{~cm}(\mathrm{SD}=3.2)$, but the standard deviation increased by 0.2 . The best result was $51 \mathrm{~cm}$ and the weakest $43 \mathrm{~cm}$.

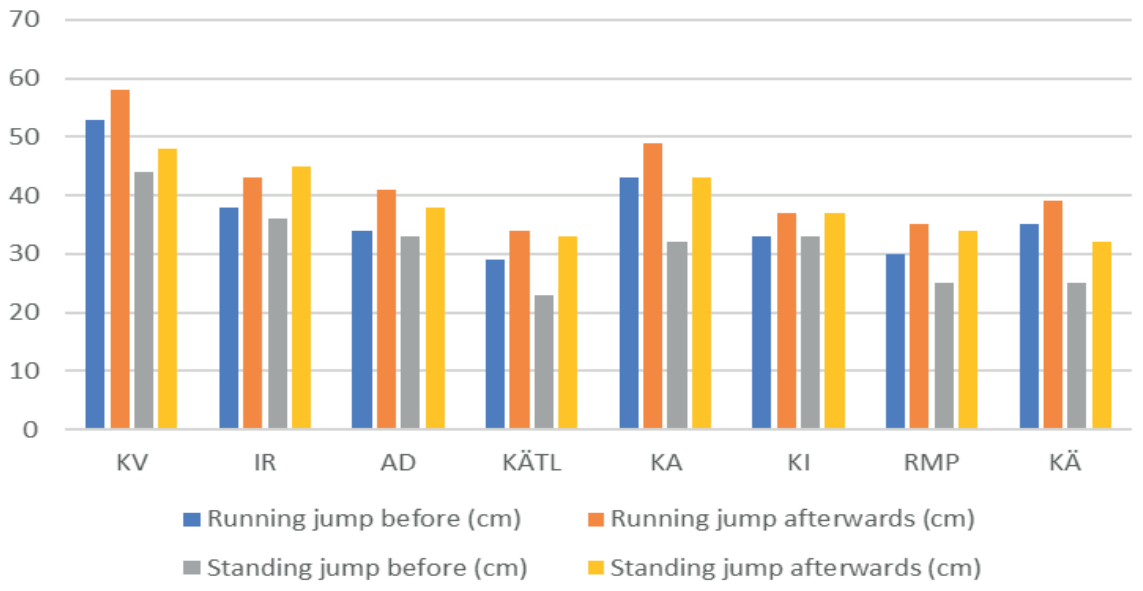

Figure 3. Jumping ability of experimental group girls (Kadrina Sports Club) before and after attending the programme

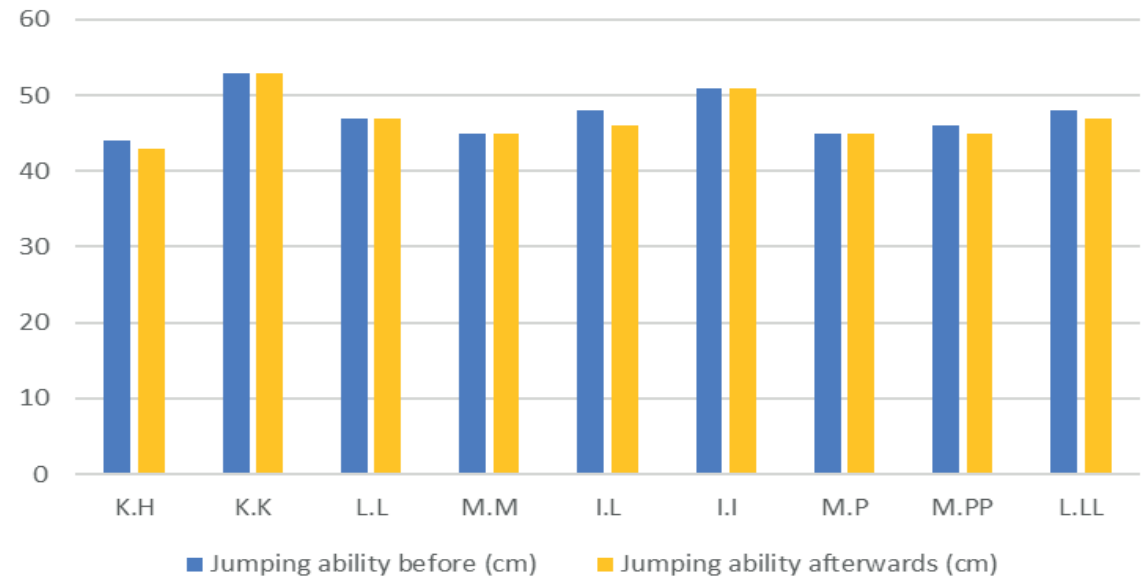

Figure 4. Control group girls' jumping ability from attack steps at the first and the second measuring 


\section{T-test results}

The jumping ability of experimental group boys and girls (Kadrina Sports Club) before and after completing the programme was assessed by the t-test. The differences in mean indicators of boys jump from attack steps before and after attending the programme were statistically significant $(\mathrm{p}=<0.05)$. The differences in mean indicators of standing jump before and after attending the programme were also statistically significant $(\mathrm{p}=<0.05)$.

The differences in mean indicators of Kadrina Sports Club girls jump from attack steps before and after attending the programme were statistically significant $(\mathrm{p}=<0.05)$. The differences in mean indicators of standing jump before and after attending the programme were also statistically significant $(\mathrm{p}=<0.05)$.

\section{DISCUSSION}

After attending the programme, the mean standing jump ability of Kadrina Sports Club boys improved by $6.2 \mathrm{~cm}$ and jumping ability from attack steps increased by $7.8 \mathrm{~cm}$. In girls, the standing jump ability improved by $7.4 \mathrm{~cm}$ and jumping ability from attack steps by $5.1 \mathrm{~cm}$; the changes were statistically significant. We compared our results with Sylvia Tammerik's study [6]. She used the same jumping ability development programme for U-16 age class players, achieving an improvement of standing jump results by $4 \mathrm{~cm}$ and running jump results by $5 \mathrm{~cm}$. According to our study, the girls' standing jump results had improved by $7.4 \mathrm{~cm}$, thus more than the results of jump from attack steps $(5.1 \mathrm{~cm})$. The mean playing experience of Kadrina Sports Club girls was 2 years and of S. Tammerik's subjects 3.8 years. Here, it could be stated that the weaker jump results of Kadrina girls from attack steps could be caused by their less skilful jumping technique - they did not know how to give themselves impetus by using the arms.

After 54 days of jumping ability development programme, the mean vertical jumping ability of the experimental group of Kadrina Sports Club children had grown at attack steps jump by $6.5 \mathrm{~cm}$ and at standing jump by $6.8 \mathrm{~cm}$. Boys improved their vertical standing jump result by $6.2 \mathrm{~cm}$ and vertical jump from attack steps by $7.8 \mathrm{~cm}$. Girls' vertical standing jump improved by $7.4 \mathrm{~cm}$ and vertical jump from attack steps by $5.1 \mathrm{~cm}$; the changes were statistically significant.

In the control group, the children of Tallinn Kalev Sports Society, who did not attend the jumping ability development programme but continued their usual practice, jumping ability did not change statistically significantly neither in boys nor in girls. 
A. V. Belyayev and L. Bulykina's jumping ability development programme proved to be suitable to be used in an adapted version for developing 12-14-year-old volleyball players' vertical jumping ability.

\section{REFERENCES}

1. Belyayev A.V., Bulykina L.V. (2004). Teoriya i praktika fizichskoy kultury [Theory and Practice of Physical Culture]. Moscow: TVT Division, 3, 27-38.

2. González-Ravé J.M., Arija A., Clemente-Suarez V. (2011). Seasonal changes in jump performance and body composition in women volleyball players. J Strength Cond Res, 25 (6), 1492-1501. https://doi.org/10.1519/JSC.0b013e3181da77f6

3. Rikberg A., Raudsepp L., Kais K. (2011). Congruence of actual and retrospective reports of precompetition affect and anxiety for young volleyball players. Percept Mot Skills, 112 (1), 44-54. https://doi.org/10.2466/05.20.PMS.112.1.44-54

4. Sattler T., Hadžić V., Dervišević E., Markovic G. (2015). Vertical jump performance of professional male and female volleyball players: effects of playing position and competition level. J Strength Cond Res, 29 (6), 1486-1493. https://doi.org/10.1519/JSC.0000000000000781

5. Martel G.F., Harmer M.L., Logan J.M., Parker C.B. (2005). Aquatic plyometric training increases vertical jump in female volleyball players. Med Sci Sports Exerc, 37 (10), 1814-1819. https://doi.org/10.1249/01.mss.0000184289.87574.60

6. Tammerik S. (2015). Hüppevõime arendusprogrammi mõju naisvõrkpallurite hüppevõimele ja antropomeetrilistele näitajatele. Master's thesis. Tallinn University.

7. Young W., MacDonald C., Heggen T., Fitzpatrick J. (1997). An evaluation of the specificity, validity and reliability of jumping tests. J Sports Med Phys Fitness, 37 (4), 240-245.

\section{Address for correspondence:}

Raini Stamm

Tallinn University

School of Natural Sciences and Health

Narva Street 29, 10120 Tallinn, Estonia

E-mail: raini@tlu.ee 